\title{
What is the status quo of high-risk behaviors among male adolescents in the South of Iran?: A cross-sectional study in Bandar Bushehr, Iran
}

\author{
Research Article
}

\author{
Ahmad Sotoudeh $^{1}$, Mojtaba Fattahi Ardakani ${ }^{2}$, Ali Asadian ${ }^{3}$, Nayereh Kasiri ${ }^{45^{*}}$, Kamel Ghobadi ${ }^{6}$ \\ 1. Department of Public Health, School of Public Health, Bushehr University of Medical Sciences, Bushehr, Iran \\ 2. Diabetes Research Center, Shahid Sadoughi University of Medical Sciences, Yazd, Iran \\ 3. Department of Health Education and Health PromotionSchool of Public Health, \\ Shahid Sadoughi University of Medical Sciences, Yazd, Iran \\ 4. Department of Public Health, School of Public Health, \\ Torbat Heydariyeh University of Medical Sciences, Torbat Heydariyeh, Iran \\ 5. Health Sciences Research Center, Torbat Heydariyeh University of Medical Sciences, Torbat Heydariyeh, Iran \\ 6. Department of Health Education and Health Promotion, School of Public Health, \\ Isfahan University of Medical Sciences, Isfahan, Iran
}

\begin{abstract}
Introduction: Adolescents are the most vulnerable population in society to high-risk behaviors. It is essential to explore male adolescents' state of health so as to establish this health well. The present research aimed to explore the prevalence of high-risk behaviors among male adolescents in the south of Iran. Methods: The present cross-sectional research employed a random multi-stratified sampling method to select subjects from male students of secondary schools ( $2^{\text {nd }}$ grade) in Bushehr in 2017. The data collection instrument was a questionnaire comprised of two parts. The first part explored background information and the second monitored adolescents' high-risk behaviors. Once the reliability and validity of the questionnaire were confirmed, the collected data were analyzed in SPSS20 using ANOVA test and Tukey post-hoc test. Results: The majority of subjects belonged to the 16 yearold age group. The highest frequency of high-risk behaviors in male adolescents involved physical contact and struggle out of school (22.81\%), hookah consumption within a month $(19.62 \%)$, physical contact and struggle at school within a year $(18.30 \%)$ and smoking cigarettes out of school in a month $(11.14 \%)$. Conclusion: The prevalence of high-risk behaviors among male adolescents was for physical contact out of school in a year, hookah consumption in a month and physical contact at school in a year. It is suggested to conduct qualitative research to recognize why adolescents show tendency to risky behaviors and to reduce such behaviors.
\end{abstract}

Keywords: Prevalence, high-risk behaviors, adolescents, cross-sectional study.

\section{Introduction}

Adolescence is a critical age in life especially in terms of physical, mental and social development. At this stage, one gets to know about certain issues, behaviors and assumptions in mind for the first time. Such issues have not made any sense ever before (1). One gets to behave in a certain way, try different roles, keeps a distance from adults and occasionally breaks the rules (2). Such affairs are often accompanied by risky behaviors that threaten one's present and future health. Drug abuse, violence and risky sexual affairs account for a high rate of mortalities in adolescence (3). High-risk behaviors are those that put one's health at risk (4). They include a wide range of damaging behaviors such as drug abuse, social aggression, physical contact with others, self-damage and illegal sex affairs (5). A great many victims of high risk

*Corresponding Author:

Nayereh Kasiri,

Department of Health Education and Health Promotion,

School of Public Health,

Isfahan University of Medical Sciences,

Isfahan, Iran

Email id: kasirin1@,thums.ac.ir behaviors in future are adolescents today (3). Tendency to risky behaviors is in fact a kind of escape from effective encounter with tense conditions which might lead to such adverse effects as AIDS or addiction and can be followed by irreparable social and psychological damages. World health Organization (WHO) considered cigarette smoking, tobacco consumption, eating greasy and low-fiber food, lack of physical activity, alcohol consumption, high-risk sex affairs, drug abuse and so on as high-risk behaviors (6).

Adolescents' health is of a great significance due to their large population. Adolescence is the right time to develop well-established healthy behaviors. Thus, persisting in the prevention of risky behaviors and establishment of healthy behaviors, non-contagious damages can be avoided $(7,8)$. A body of research at a global scale revealed that high-risk behaviors often begin before the age of 18 and include such behaviors as cigarette, alcohol and drug consumption (8-12). The mean age of beginning to smoke cigarettes in Iran among smokers is 16.6 years (13). Moreover, the majority of addicts, begin drug abuse between the age of 17 and 22 (14-15). A body of related research indicated that early cigarette smoking would increase the probability of consuming alcohol and drugs as well as 
educational problems among teenagers (16). As adolescents are among vulnerable populations in society to high-risk behaviors, it is evident that any physical or mental damage to this population would lead to slower social growth. Furthermore, adolescents' lacking physical and mental health in the long run can negatively affect health in society. Therefore, the present research was conducted to evaluate high-risk behaviors among male adolescents in the south-west of Iran.

\section{Materials and methods}

The present research was qualitative in type and its target population was all male secondary school students ( $2^{\text {nd }}$ grade) in Bushehr in 2017. They were 11,825 in number. Yet, a sample of 386 subjects was selected according to Morgan \& Krejcie's formula. The sampling method was random multi-stratified. The inclusion criteria were permanent residence in Bushehr and consent to take part in the study. When the sample size was estimated and the required permissions were gained from the education office of Bushehr County, a number of schools were randomly selected from the total number of schools in Bushehr and then again a number of classes were randomly selected from these schools. Subsequently, the questionnaires were submitted to the students.

The data collection instrument was a questionnaire comprised of two parts, the first of which enquired about a respondent's demographic information (e.g. age, grade of school, parents' education, field of study, experience of consuming cigarettes, alcohol, hookah, heroin for at least one time, source of gaining health-related information and experience of physical activity). The second part was the high-risk behavior monitoring system questionnaire, comprised of 90 items that explored teenagers' risky behaviors in different domains such as security, violence (challenging behavior), suicide, cigarette consumption, alcohol consumption, illegal drug abuse, high-risk sexual behaviors and lack of physical activity (17-18). In the present research, items related to hookah consumption were added due to the high prevalence of hookah consumption in the south-west of Iran. To check the validity of the questionnaire, it was availed to a panel of experts $(n=9)$. The content validity index and ratio were estimated which were respectively .86 and .92 . To test the reliability of the instrument, it was piloted on 30 male secondary school students $\left(2^{\text {nd }}\right.$ grade) and the data were analyzed through Cronbach's alpha which was estimated to be .83 interpreted as acceptable.

Participation in the study was voluntary and the subjects were ensured of the confidentiality of the information they provided. The collected data entered SPSS20 for statistical analysis. Descriptive statistics as well as inferential statistics were used including ANOVA and Tukey post-hoc test to explore the interrelationship of demographic information and the target high-risk behaviors. The significance level of all tests was set at 0.05 .

\section{Result}

A sample was 386 subjects participated in this study. From among this, 7 filled out the questionnaires incompletely and 2 did not return them at all and were excluded from the study. The return rate was $97.6 \%$.

The mean age of the participants was 16.7 years ( $\pm 1.4 \mathrm{SD}) .132$ subjects $(35.01 \%)$ were studying in the $10^{\text {th }}$ year, 125 subjects $(33.15 \%)$ in the $11^{\text {th }}$ year and 120 subjects $(31.83 \%)$ in the $12^{\text {th }}$ year. The education level of $68 \%$ of mothers and $61 \%$ of fathers was below Bachelor's degree (see Table 1).

Table 1: Male adolescent subjects' demographic information

\begin{tabular}{|c|c|c|c|}
\hline \multicolumn{2}{|c|}{ Demographic variable } & f. & $\%$ \\
\hline \multirow[t]{3}{*}{ Age } & 15 years & 109 & 28.91 \\
\hline & 16 years & 141 & 37.40 \\
\hline & $\geq 17$ years & 127 & 33.68 \\
\hline \multirow[t]{4}{*}{ Field of study } & $\begin{array}{l}\text { Technical } \\
\text { school }\end{array}$ & 101 & 26.79 \\
\hline & Math & 96 & 25.46 \\
\hline & $\begin{array}{l}\text { Experimental } \\
\text { sciences }\end{array}$ & 83 & 22.01 \\
\hline & Humanities & 97 & 25.72 \\
\hline \multirow[t]{5}{*}{$\begin{array}{l}\text { Mother's } \\
\text { education }\end{array}$} & $\begin{array}{l}\text { Elementary } \\
\text { school }\end{array}$ & 26 & 6.89 \\
\hline & High school & 156 & 41.37 \\
\hline & $\begin{array}{l}\text { Associate } \\
\text { degree }\end{array}$ & 78 & 20.68 \\
\hline & B.A./B.S. & 83 & 22.01 \\
\hline & $\geq$ M.A./M.S. & 34 & 9.01 \\
\hline \multirow[t]{5}{*}{$\begin{array}{l}\text { Father's } \\
\text { education }\end{array}$} & $\begin{array}{l}\text { Elementary } \\
\text { school }\end{array}$ & 21 & 5.57 \\
\hline & High school & 99 & 26.25 \\
\hline & $\begin{array}{l}\text { Associate } \\
\text { degree }\end{array}$ & 110 & 29.17 \\
\hline & B.A./B.S. & 94 & 24.93 \\
\hline & $\geq$ M.A./M.S. & 53 & 14.05 \\
\hline \multirow[t]{4}{*}{ Rank in birth } & $1^{\text {st }}$ & 127 & 33.68 \\
\hline & $2^{\text {nd }}$ & 112 & 29.70 \\
\hline & $3^{\text {rd }}$ & 80 & 21.22 \\
\hline & $4^{\text {th }}$ & 58 & 15.38 \\
\hline \multirow{4}{*}{$\begin{array}{l}\text { Father's } \\
\text { occupation }\end{array}$} & Employed & 114 & 30.23 \\
\hline & Retired & 44 & 11.67 \\
\hline & Freelance & 205 & 54.37 \\
\hline & Unemployed & 14 & 3.71 \\
\hline \multirow{2}{*}{$\begin{array}{l}\text { Current state } \\
\text { of } \quad \text { cigarette } \\
\text { or hookah } \\
\text { consumption }\end{array}$} & Yes & 84 & 22.28 \\
\hline & no & 293 & 77.71 \\
\hline
\end{tabular}

The results showed that the highest frequency of high-risk behaviors respectively belonged to physical contact/struggle out of school within a year, hookah consumption within a month and physical contact/ struggle in school within a year. 
Table 2: Distribution of high-risk behaviors among male adolescent subjects

\begin{tabular}{|l|l|l|l|l|l|l|}
\hline & $\mathbf{0}$ & \multicolumn{2}{l|}{ once } & \multicolumn{2}{l|}{ Twice or more } \\
\cline { 2 - 7 } & f. & \% & f. & $\%$ & f. & $\%$ \\
\hline Physical contact/struggle out of school in a year & 218 & 57.82 & 73 & 19.36 & 86 & 22.81 \\
\hline Physical contact/struggle inside school in a year & 217 & 57.55 & 91 & 24.13 & 69 & 18.30 \\
\hline Having cold weapon at school in a month & 320 & 84.88 & 36 & 9.54 & 21 & 8.57 \\
\hline Smoking cigarettes at school in a month & 307 & 81.43 & 39 & 10.34 & 31 & 8.22 \\
\hline Smoking cigarettes outside school in a month & 288 & 76.39 & 47 & 12.46 & 42 & 11.14 \\
\hline Hookah consumption in a month & 235 & 62.33 & 68 & 18.03 & 74 & 19.62 \\
\hline Alcohol consumption in a month & 327 & 86.73 & 31 & 8.22 & 19 & 5.03 \\
\hline Drug abuse in a month & 337 & 89.38 & 24 & 6.36 & 16 & 4.24 \\
\hline
\end{tabular}

The prevalence of wearing a seat-belt while in a car was estimated as $23.34 \%$. That of wearing a helmet while riding a motorcycle was $11.40 \%$. The prevalence of wearing a helmet while riding a bicycle was $4.24 \%$.

Table 3: Distribution of male adolescent subjects' wearing a seat-belt and/or helmet

\begin{tabular}{|l|l|l|l|l|l|l|l|l|}
\hline Variable & \multicolumn{2}{|l|}{ never } & \multicolumn{2}{l|}{ seldom } & \multicolumn{2}{l|}{ often } & \multicolumn{2}{l|}{ always } \\
\cline { 2 - 9 } & f. & $\%$ & f. & $\%$ & f. & $\%$ & f. & $\%$ \\
\hline Wearing a seat-belt while sitting in a car & 79 & 20.95 & 114 & 30.23 & 96 & 25.46 & 88 & 23.34 \\
\hline Wearing a helmet while riding a motorcycle & 124 & 32.89 & 125 & 33.15 & 85 & 22.54 & 43 & 11.40 \\
\hline Wearing a helmet while riding a bicycle & 244 & 64.72 & 89 & 23.60 & 28 & 7.42 & 16 & 4.24 \\
\hline
\end{tabular}

The present findings revealed that the prevalence of physical contact/struggle outside school within a year and cigarette smoking outside school in a month was higher in students of technical schools than others. The correlation of technical studies and physical contact/ struggle outside school within a year's time was statistically significant $(\mathrm{p}=0.0001)$. Yet, the correlation of cigarette smoking outside school in a month and technical studies was not statistically significant $(p>0.05)$. Adolescents whose fathers were employed reported a lower rate of hookah consumption within a month and this correlation was statistically significant $(p=0.003)$. However, the correlation between physical contact/struggle outside school in a year's time and father's occupation was not statistically significant $(p>0.05)$. Adolescents who were the $3^{\text {rd }}$ child of the family showed to have more physical contact/struggle outside school with a year. Yet, the correlation of birth rank and physical contact/struggle outside school was not statistically significant $(\mathrm{p}>.05)$. Adolescents who were the $4^{\text {th }}$ child of the family had a higher rate of smoking cigarettes outside school in a month. Yet, this correlation was not statistically significant $(\mathrm{p}>0.05)$.

\section{Discussion}

The present research aimed to explore the highrisk behaviors of male adolescents in the south-west of Iran in 2017. In a sample of 377 male adolescents, 84 $(22.28 \%)$ reported to be cigarette or hookah consumers at the time of study. Besides, the rate of hookah consumption within a month and outside school were respectively reported to be $19.62 \%$ and $11.14 \%$. In a body of related research among Iranian adolescents including one conducted in Qazvin, the prevalence of cigarette consumption was reported to be $9.9 \%$ which is similar to the present findings. However, the rate of hookah consumption was estimated as $36.9 \%$ which exceeds the estimated rate in the present study (19).

Another similar study was carried out on male and female adolescents in Tehran and found the prevalence of smoking cigarettes as $35.2 \%$ and $51.5 \%$, respectively (20). This rate is higher than that of the present research concerning cigarette and hookah consumption. Another investigation of cigarette and hookah consumption in Tehrani adolescents found the prevalence rate of the two as $12 \%$ and $30 \%$, respectively (21). The prevalence of cigarette and hookah smoking among female adolescents in the south -east of Iran was $8 \%$ and $10 \%$, respectively (22). Cigarette consumption among American adolescents in 2011 was estimated at 18\% (18). In England, tobacco consumption among susceptible and insusceptible youth was $15 \%$ and $8 \%$, respectively (23). Cigarette and hookah consumption are among behaviors that adversely affect adolescents' physical and mental health. This population is among the most susceptible populations in society to high-risk behaviors. Therefore, any damage to this population either physical or mental can have negative consequences for the development of human forces. Unfortunately, in Iran hookah services are provided publicly in communal areas such as restaurants. Although offering public services for hookah is prohibited, there is little surveillance and thus it is widely prevalent. Widespread public use at a social scale has significantly reduced the indecent look of the behavior, which in its own turn, can increase the prevalence of this behavior among the susceptible population of adolescents. Occasionally, parents accompany teenagers in smoking hookahs, which can further intensify the behavior in teenagers. Thus, raising 
parents' awareness of the adverse effects of hookah consumption and better surveillance by state institutions over restaurants and other public places can cut down on the prevalence of hookah consumption in society especially adolescents (24).

In the present research, the prevalence of drug abuse and alcohol consumption was low. In a body of research in Iran including a study of university students in Dezful and female adolescents in the south-east of Iran, the rate of drug and alcohol abuse was respectively $3.7 \%$ and $4.85 \%(22,25)$ which is in line with the present findings. Some other research on adolescents in Qazvin pointed to the low rate of drug and alcohol abuse (19). However, the results of other Iranian studies reported the rate of alcohol consumption among Tehrani adolescents as $27.4 \%$ and $10 \%(20-21)$. This is significantly higher than the present findings. In similar works of similar research at a global scale, the prevalence of alcohol, marijuana and drug abuse was reported to be between 11 and 38.7\% (18, 23-27). Some other research about American high school students in 2016 found the rate of alcohol and marijuana consumption 23.33 and $13.18 \%$, respectively (28).

Different prevalence of high-risk behaviors in comparative studies of such behaviors as drug or alcohol abuse in different countries can be due to differing cultural, social, economic and contextual circumstances. It seems that the dominant sociocultural conditions in any society can affect the prevalence of consumption and self-report of such behaviors.

In the present research, the highest frequency of high-risk behaviors belonged respectively to physical contact/struggle outside school (22.81\%) and physical contact/struggle inside school within a year's time $(18.30 \%)$. Physical contact outside home was among the most prevalent high-risk behaviors (28.1\%) among adolescents in Tehran (20), which is consistent with the present findings. The prevalence of physical violence in a study in Isfahan among adolescents was reported to be $33.3 \%$ (29). In a comparative body of research, Iran shows to suffer from the highest rate of violence of all developing countries (30-35). An extensive work of research showed that the rate of physical violence ranged from $27 \%$ to $37 \%$ in low-income and below average income countries (36). An investigation in America showed the prevalence of violence among students was 7.8\% (37) which is lower than the present finding.

The results of the present research indicate that the prevalence of violence among Iranian adolescents follows a similar fashion, and the rate of physical contact and violence is significantly higher than other low to average income countries. It seems that the role of individual, social and familial factors in the emergence and development of violence is undeniable. Thus, interventional strategies should target different individual, familial and social levels. Individually, it is essential to enhance coping skills including the skill to say no, to control relations, control anger and violence. Family plays a key role in transcending adolescents. Family-based educational programs are of utmost importance in reducing high-risk behaviors.

In the present research, the rate of wearing a helmet while sitting in a car or riding a motorcycle/ bicycle was found to be $11.4 \%$ and $4.24 \%$, respectively. Motorcycle and bicycle riders did not feel obliged to wear a helmet while the foremost risk factor in using such protectives is refraining from wearing a helmet. The most effective way to reduce the risks of accidents is wearing a helmet. Thus, it is essential to provide necessary education and culture with the help of families and the traffic police. Considering the fact that the majority of motorcyclists are in their teens, this age group show a voracious appetite for risky movements.

One limitation of the present research was the self -rating nature of the questionnaire which can lead to biased data. Another limitation can be the underestimation of high-risk behaviors due to cultural barriers, social norms, fear and other social barriers. Moreover, the present research was conducted in Bushehr in the south of Iran and the findings are not generalizable to the whole population of Iranian adolescents.

\section{Conclusion}

The present research aimed to explore the prevalence of high-risk behaviors in the south of Iran. A number of high-risk behaviors including physical contact/struggle outside school in a year, hookah consumption in a month and physical contact/struggle inside school in a year were found to be the most prevalent. High-risk behaviors are among issues that require considerable attention and cooperative interaction for planning and implementing interventions. Moreover, qualitative research can help to recognize the underlying causes of adolescents' tendency to high-risk behaviors and to find appropriate ways to prevent and reduce many psychological damages of high-risk behaviors.

\section{Acknowledgements}

The present paper is derived from a research project approved by the deputy of research and technology in Bushehr University of medical sciences (registration code: IR.BPUMS.REC.1394.160). The present authors wish to express gratitude to the education office, school principals and teachers in Bushehr as well as the students who participated in this study. The gratitude is extended to the deputy of research and technology in Bushehr University of medical sciences for cooperation to approve this project and financial sponsorship of this research project. 


\section{References}

1. Kann L, Kinchen S, Shanklin SL, Flint KH, Kawkins J, Harris WA, et al, Youth risk behavior surveillance-United States, 2013. Morbidity and Mortality Weekly Report (MMWR). 2014; 63(4): 1168.

2. Fernandez-Fuertes AA, Fuertes A, Physical and psychological aggression in dating relationships of Spanish adolescents: Motives and consequences. Child Abuse \& Neglect. 2010; 34(3): 183-191.

3. Hamby S, Turner H, Measuring teen dating violence in males and females: Insights from the national survey of children's exposure to violence. Psychology of Violence. 2013; 3(4): 323-339

4. Kernsmith PD, Tolman RM, Attitudinal correlates of girls' use of violence in teen dating relationships. Violence Against Women. 2011; 17(4): 500-516.

5. Wincentak K, Connolly J, Card N, Teen Dating Violence: A Meta-Analytic Review of Prevalence Rates. Psychology of Violence. Advance online publication. 2016; 7(2): 1-18.

6. Carney T, Myers BJ, Louw J, Okwundu CI, Brief school-based interventions and behavioural outcomes for substance-using adolescents. Cochrane database of systematic reviews. DOI: 10.1002/14651858.CD008969

7. Zweig J M, Dank M., Yahner J, Lachman P, The rate of cyber dating abuse among teens and how it relates to other forms of teen dating violence. Journal of Youth and Adolescence. 2013; 42(7): 1063-1077.

8. Miller JW, Naimi TS, Brewer RD, Jones SE, Binge drinking and associated health risk behaviors among high school students. Pediatrics. 2007; 119(1): 7685.

9. Cogollo Z, Gómez-Bustamante EM, Health risk behavior pattern among students from Cartagena, Colombia: prevalence and associated variables .Revista da Escola de Enfermagem da USP. 2013; 47(4): 830-5.

10. Hosseini M, Maghami M, Kelishadi R, Motlagh ME, Khoshbin S, Amirkhani A, et al, First Report on Self-Rated Health in a Nationally-Representative Sample of Iranian Adolescents: The CASPIAN-iii study. International Journal of Preventive Medicine. 2013; 4(2): 146-52.

11. Theresa A, Alcohol, Drugs, and Links to Sexual Risk Behavior among a sample of Virgina college students. Journal of Drug Education.2011; 41: 1-16.

12. Mhamdi S, Wolfcarius-Khiari G, Mhalla S, Ben Salem K, Soltani SM, Prevalence and predictors of smoking among adolescent schoolchildren in Monastir, Tunisia. Eastern Mediterranean Health Journal.2011; 17(6): 523-29.

13. Gardner F, Montgomery P, Knerr W, Transporting Evidence-Based Parenting Programs for Child Problem Behavior (Age 3-10) Between Countries:
Systematic Review and Meta-Analysis. Journal of Clinical Child and Adolescent Psychology. 2016;45 (6): 749-762.

14. UNICEF. The State of the World's Children: adolescence, an age of opportunity. New York: Unicef, 2011.

15. Meinck F, Cluver LD, Boyes ME, Ndhlovu LD, Risk and protective factors for physical and emotional abuse victimization amongst vulnerable children in South Africa. Child Abuse Review 2015; 24(3):182-197.

16. Patrick ME, Cronce JM, Fairlie AM, Atkins DC, Day-today variations in high-intensity drinking, expectancies, and positive and negative alcoholrelated consequences. Addictive Behavior.2016; $58: 110-116$.

17. Soleymaninia L. The relationship between high risk behavior and mental health in adolescent students.MA Thesis in psychology ,Ulum Behzisti University, Tehran, Iran.2006.

18. Center for Disease control and Prevention. National Youth Risk Behavior Survey. 2015. Available from:http://www.cdc.gov/healthyyouth/schoolhealth/ index.htm.

19. Esmaielzadeh H, Asadi M, Miri N, Keramatkar M. Prevalence of High Risk Behaviors Among High School Students of Qazvin in 2012. Iranian Journal of Epidemiology 2014; 10(3): 75-82.

20. Rashid K, Epidemiology of High-Risk Behaviors among Tehran Adolescent Girls and Boys. Social Welfare. 2015; 15 (57):31-55

21. Barikani, A, High risk behaviors in adolescent students in Tehran. Iranian Journal of Psychiatry and Clinical Psychology, 2008; 14, 192-198.

22. Shahraki-Sanavi F, Rakhshani F, AnsariMoghaddam AR, Mohammadi M, Khazaei Feizabad AR, Prevalence of health-risk behaviors among teen girls in Southeastern Iran. Electronic Physician 2018; 10(6): 6988-6996

23. Currie K, Bray I, Health inequalities, risky behaviours and protective factors in adolescents: An analysis of secondary survey data from the UK. Public health. 2019;1(170):133-139.

24. Setoudeh A, Tahmasebi R, Noroozi A, Effect of Education by Health Volunteers on Reducing Waterpipe Use among Women in Bushehr: An Application of Health Belief Model. Journal of Hayat. 2016; 22 (1):50-64

25. Khazaei Z, Mohammad AT, Zeynab S, Molaei Z, Khazaei S, Goodarzi E, et al, Prevalence of risky behaviors and related factors among students of Dezful University of Medical Sciences in 2014. Iranian Journal of Psychiatry. 2017; 12(3):188-93.

26. Dos Santos WJ, da Silva Coêlho WM, do Bonfim $\mathrm{CV}$, da Costa de Ceballos AG. Alcohol and risky behavior in traffic among motorcyclists involved in accidents in a city in northeastern Brazil. Traffic 
Injury Prevention. 2019; 20(3): 233-237

27. Kann L, McManus T, Harris WA, Shanklin SL, Flint $\mathrm{KH}$, Hawkins J, et al, Youth Risk Behavior Surveillance - United States 2017. Morbidity and Mortality Weekly Report (MMWR). 2018; 67(8):1114

28. Cornell D, Huang F, Authoritative School Climate and High School Student Risk Behavior: A Crosssectional Multi-level Analysis of Student SelfReports. Journal of Youth Adolescence.2016;45(11): 2246-2259

29. Golshiri P, Farajzadegan Z, Tavakoli A, Heidari K, Youth Violence and Related Risk Factors: A Crosssectional Study in 2800 Adolescents. Advanced Biomedical Research. 2018; 7:138

30. Fakhari A, Tabatabavakili M, Javid YS, Farhang S, Family violence influences mental health of school girls in Iran: Results of a preliminary study. Asian Journal of Psychiatry. 2012; 5(1):24-7

31. Yang L, Zhang Y, Xi B, Bovet P,Physical fighting and associated factors among adolescents aged 13-15 years in six Western Pacific countries. International Journal of Environmental Research and Public Health 2017;14(11):1-10.
32. 32. Mat Hussin SF, Abd Aziz NS, Hasim H, Sahril $\mathrm{N}$, Prevalence and factors associated with physical fighting among Malaysian adolescents. Asia-Pacific Journal of Public Health. 2014; 26(5S) 108S-115S.

33. Fraga S, Ramos E, Dias S, Barros H, Physical fighting among school-going portuguese adolescents: Social and behavioural correlates. Preventive Medicine .2011; 52(5):401-4.

34. Rudatsikira E, Muula AS, Siziya S, Variables associated with physical fighting among US high-school students. Clinical Practice and Epidemiology in Mental Health. 2008; 4(16)1-8

35. Celedonia KL, Wilson ML, El Gammal HA, Hagras AM, Physical fighting among Egyptian adolescents: Social and demographic correlates among a nationally representative sample. PeerJ 2013; $1: \mathrm{e} 125$.

36. World Health Organization, Global School-Based Student Health Survey (GSHS). Geneva: World Health Organization; 2009.

37. Kann L, McManus T, Harris WA, Shanklin SL, Flint KH, Hawkins J, et al, Youth risk behavior surveillance - United States, 2015. Morbidity and Mortality Weekly Report (MMWR). 2016; 65(6);1174. 